\title{
Pattern of occurrence of jaw cysts and cyst-like lesions at the University of Nairobi Dental Hospital: A 10-year histopathologic audit
}

\author{
Cyrus S. Micha, Mark L. Chindia, David O. Awange, Elizabeth Dimba, Tom M. Osundwa, \\ Josiah G. Otwoma \\ Department of Oral \& Maxillofacial Surgery and Oral Medicine, Oral Pathology School of Dental Sciences, University of Nairobi, \\ Kenya \\ Email:michacyrus@yahoo.com,profchindia@yahoo.com
}

Received 15 July 2011; revised 31 August 2011; accepted 7 March 2012

\begin{abstract}
Background: Jaw cysts and cyst-like lesions cause facial deformity, destruction of dental tissues and affect masticatory and phonation functions. These adversely erode patients' psycho-social status; create low self-esteem and may change one's facial identity and appearance. Objective: To determine the histopathologic characteristics, variants and demographic pattern of jaw cysts and cyst-like lesions at the University of Nairobi Dental Hospital. Material and Method: This was an analytical and verification study that involved microscopic re-examination of all available incisional/excisional biopsy samples from January 2000 to December 2009 for histo-pathological diagnosis at the University of Nairobi Dental Hospital. Results: 187 jaw cysts and cyst-like lesions were diagnosed at the University of Nairobi Dental Hospital over the ten-year period. Keratocystic odontogenic tumours constituted $28 \%$, dentigerous cysts $25 \%$, nasopalatine duct cysts $19 \%$, radicular cysts $15 \%$, while calcifying odontogenic cysts comprised $4 \%$ of all the lesions. The rest of the lesions were between $1 \%$ and $3 \%$ of all the lesion entities. Conclusion: Keratocystic odontogenic tumours and dentigerous cysts were the most common developmental odontogenic cysts diagnosed in the ten-year period.
\end{abstract}

Keywords: Jaw Cysts; Odontogenic Cyst;

Non-Odontogenic Cysts; Dentigerous Cyst and Cyst-Like Lesions

\section{INTRODUCTION}

In the maxillofacial region, diverse cysts and cyst-like lesions have been well described and characterized worldwide. Among these lesions, odontogenic cysts (OCs) are the most commonly diagnosed entities [1]. OCs are unique in that they only affect the oral and maxillofacial region [2]. These lesions originate in the epithelial components of the odontogenic apparatus or from its remnants which are entrapped within the bone or peripheral gingival tissues [3]. They are, traditionally, classified into a developmental group which includes dentigerous cysts (DCs) that are the commonest developmental cysts and an inflammatory group which constitutes radicular cysts (RCs) as the commonest and have more male predilection. Other OCs such as the glandular odontogenic cyst (GOC), first described by Padayachee and Van Wyk in 1978 [4]; and the Paradental cyst are rarely encountered. Notably, according to the WHO classification, the term "Paradental cyst" can be applied to two distinct clinical conditions: either a lesion that involves the buccal or distal aspect of a partially erupted mandibular third molar in an adult [5] or a buccally located lesion involving the mandibular first or second permanent molar in children.

As per the conventional definition of cysts, other lesions characterized as non-odontogenic cysts (nOCs) frequently encountered include the nasolabial cysts (NLCs) anaurysmal bone cysts (ABCs) and the traumatic bone cysts (TBCs). The NLCs (also known as nasoalveolar cysts) were first describe by Zucker Kandl in 1821 while the TBCs were originally reported by Lucas in 1929 [6] and later defined by Rushton (1946) [7] as single cysts without an epithelial lining. On the other hand the ABCs were first recognized in 1942 by Jaffe and Lichtenstein [8]. However, Bernier and Bhaskar [9] reported the first case occurring in the jaw in 1958. This lesion is considered to be non-neoplastic and presumably a reactive bone lesion.

Generally, true cysts represent a pathologic cavity surrounded by epithelium, with fluid or semisolid material in its interior [10]. These lesions do not show any po- 
tential for neoplastic change. On the other hand cyst-like lesions do not, largely, have any definitive epithelial lining except the keratocystic odontogenic tumours (KCOTs) which display a definitive thin friable epithelial lining. KCOTs are common lesions that are clinically aggressive and characterized by a high frequency of recurrence $[11,12]$. One other lesion that the WHO has registered among the odontogenic cystic neoplasms is the now calcifying cystic odontogenic tumour (CCOT) formerly known as the calcifying odontogenic cyst (COC). This is an uncommon lesion with both cystic and neoplastic areas having the so-called ghost cells which that are anucleate with homogenous pale eoninophilic cytoplasm and very pale to clear areas instead of basophilic nuclei. It is a benign cystic neoplasm with an ameloblastoma-like epithelium [13].

The demographic pattern, site and frequency of occurrence of these cysts and cyst-like lesions vary depending on the type of lesion in question. The purpose of the present investigation was to document the histopathologic characteristics, variants and demographic pattern of OCs, nOCs and cyst-like lesions registered in the Division of Oral Pathology and Oral Medicine at the University of Nairobi Dental Hospital (UNDH) over a 10-year period.

\section{MATERIAL AND METHOD}

\subsection{Study Site}

The UNDH serves as a teaching centre both at undergraduate and post-graduate levels. It is a major referral institution for general dental and specialist oral and max- illofacial healthcare services in Kenya and regionally.

\subsection{Study Design}

This was an analytical and verification audit of archival samples of cysts and cyst-like jaw lesions from January 2000 to December 2009. Fresh slides were prepared from all the available blocs and the Haematoxylin and Eosin staining accomplished for histopathological analysis by two oral pathologists. Consensus diagnosis for each sample lesion was arrived at and classified accordingly. Data were then analysed utilizing the SPSS version 17 programme.

\section{RESULTS}

The present study included 187 cases of jaw cysts and cyst-like lesions among which were OCs, nOCs and cyst-like entities. The ages of the cases ranged from 4 to 87 years (mean $=25 \mathrm{yr}$ ). The male to female ratio was 1.4:1 (SD = 14.13).

There was a statistical significance of the number of cysts that occurred in males as compared to females, the site of occurrence (mandibular or maxilla), the type and proportions of the cysts and cyst-like lesions diagnosed over the study period.

In the present audit, the most commonly diagnosed OC was the DC (47 cases) indicating more male affliction (66\%) than female (34\%). Figure 1 summarizes the pattern of occurrence of DCs according to site. RCs constituted $15 \%$ of all the lesions diagnosed over the study period. Most of these cysts occurred among males (76\%)

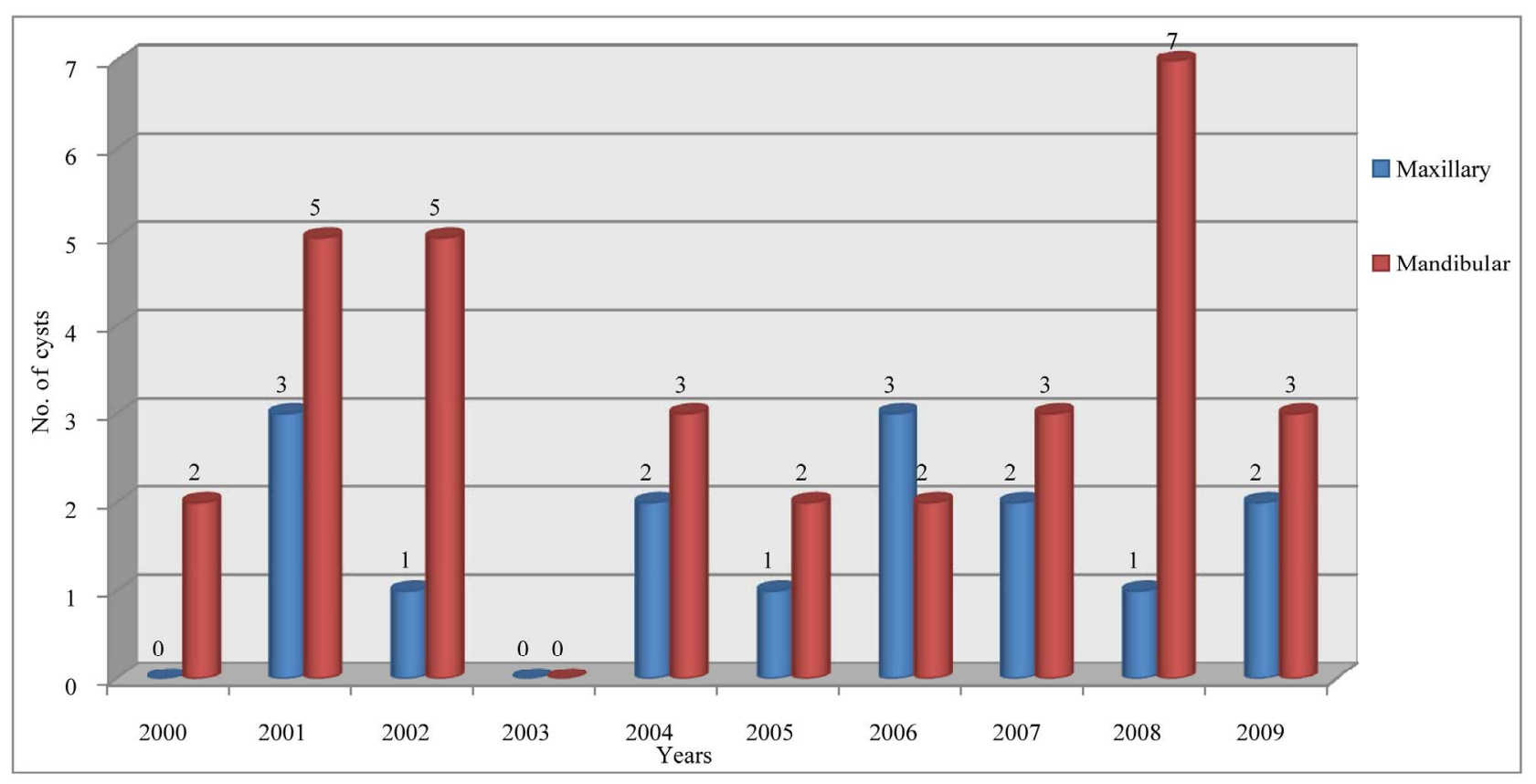

Figure 1. Pattern of occurrence of DCs over the study period according to site. 
than females (24\%), and the lesions were more common in the maxilla (72\%) than in the mandible (28\%). Remarkably, maxillary RCs were predominant among males (76\%) than females (24\%). The peak age groups at which RCs occurred were the 16 to 20 - and 36 to 40 year-old brackets with a mean of 26.6-year. Figure 2 depicts the pattern of occurrence of RCs according to age groups.

Among the nOCs, the most commonly diagnosed lesion was the nasopalatine duct cyst (NPDC) constituting $19 \%$ of all the cysts and cyst-like lesions.

Eruption cysts comprised 2\% and occurred in both genders equally; and $50 \%$ of these lesions affected those aged 11 to 25 years. As illustrated in Table 1 the rest of the described cyst entities occurred only in small numbers.

Regarding the cyst-like lesions that have been characterized to have neoplastic potential, KCOTs were predominantly diagnosed constituting $51 \%$ among males and $49 \%$ females. These tumours occurred more in the mandible (77\%) than the maxilla (23\%). Remarkably, $56 \%$ of the mandibular lesions occurred in females while maxillary tumours were more among males (58\%). Notably, $6 \%$ of the KCOTs were diagnosed with the Gorlin-Goltz syndrome. Figure 3 summarizes the pattern of occurrence of KCOTs according to gender and age groups. One other cyst-like lesion that has been characterized as a neoplasm, the CCOT (COC) constituted 4\% of all the studied lesions. Most of these lesions (71\%) occurred in females and in the maxilla predominantly in the 11 to 15 -year-old age bracket.

\section{DISCUSSION}

According to the new WHO classification of 2005 [14], KCOT and CCOT have now been reclassified as odontogenic tumours. For the sake of comparison, we maintained the previous classification system. In this study

Table 1. Summary of the range of cysts and cyst-like lesions diagnosed.

\begin{tabular}{ccc}
\hline Type of cysts & No. of cysts & $\%$ Age value \\
\hline Keratocystic odontogenic tumour (KCOT) & 53 & $28 \%$ \\
Dentigerous cyst & 47 & $25 \%$ \\
Nasopalatine duct cyst (NPDC) & 35 & $19 \%$ \\
Radicular cyst & 29 & $15 \%$ \\
Calcifying odontogenic cyst & 7 & $4 \%$ \\
Eruption cyst & 4 & $2 \%$ \\
Aneurysmal bone cyst & 3 & $2 \%$ \\
Nasolabial cyst & 3 & $2 \%$ \\
Traumatic bone cyst & 2 & $1 \%$ \\
Paradental cyst & 2 & $1 \%$ \\
Residual cyst & 1 & $0.5 \%$ \\
Gingival cyst & 1 & $0.5 \%$ \\
TOTAL & 187 & $100 \%$ \\
\hline
\end{tabular}

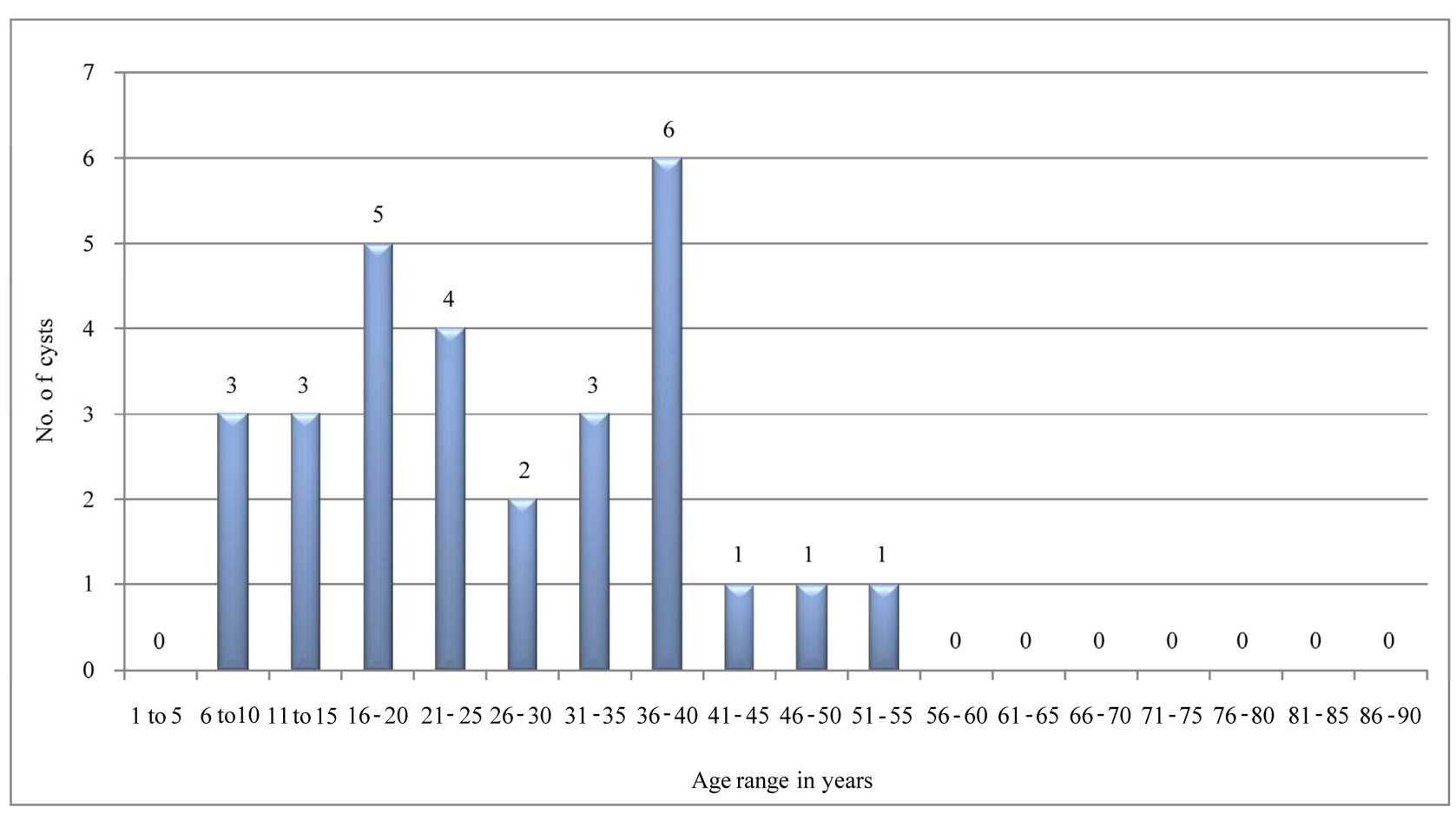

Figure 2. Pattern of oocurrence RCs according to age group. 


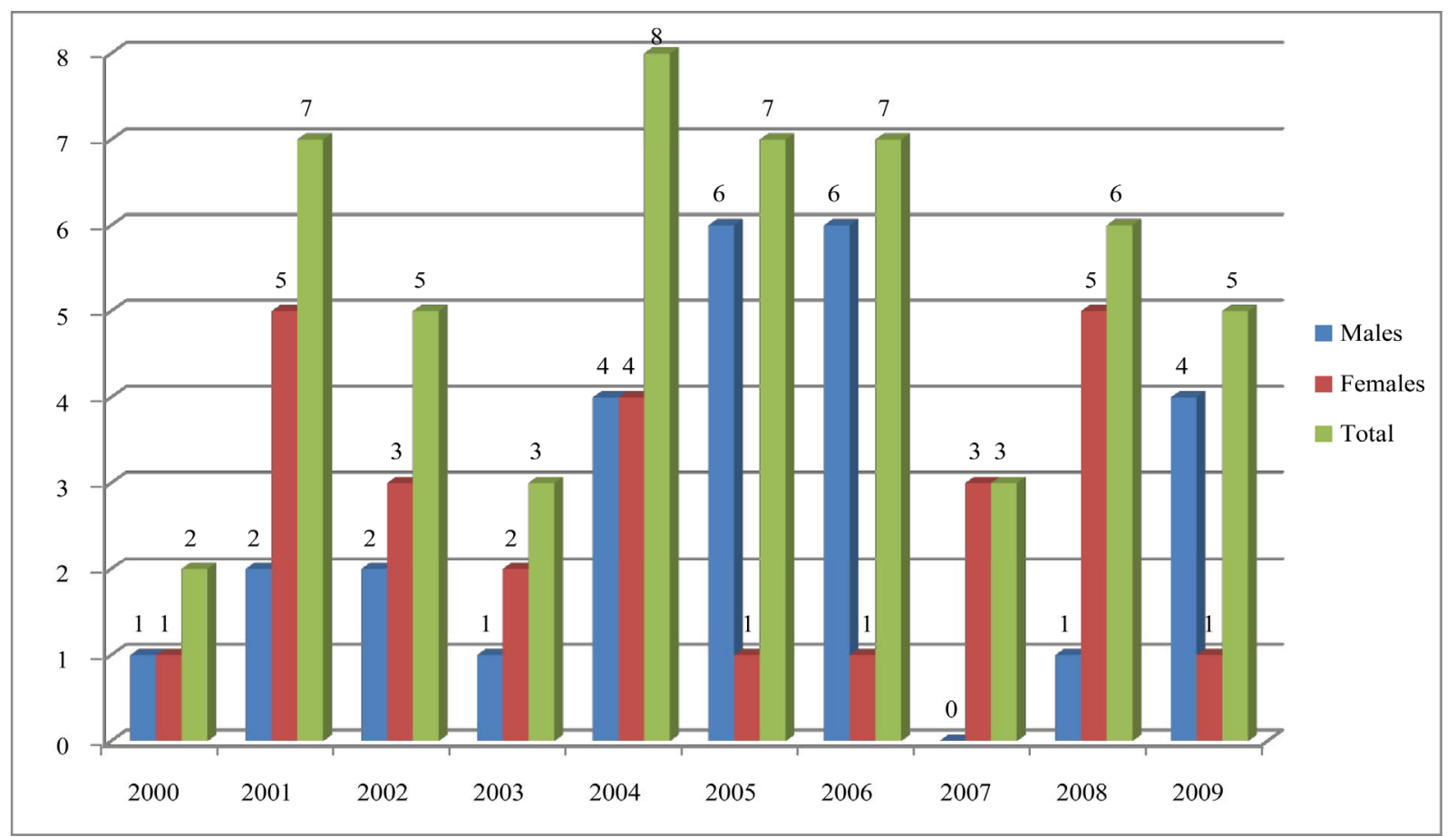

Figure 3. Summarizes the pattern of occurrence of KCOTs according to gender and age groups.

odontogenic cysts were most commonly diagnosed at 77\% compared to non-odontogenic cysts and cyst-like lesions. This is in keeping with other published data [15]. KCOT which had previously been classified as an odontogenic cyst would have been the most common at 38\% among the odontogenic cysts but currently it is a tumour hence a cyst-like lesion. This differs from findings of an earlier study in which the most commonly diagnosed cysts were RCs [15,16]. Table 2 gives a camparison of our findings and the other studies done in other countries.

DCs were the second most commonly diagnosed lesions (35\%) among the odontogenic cysts which was similar to findings in other studies [3,15-17]. Among the nOCs, the highly diagnosed lesions were the NPDCs (81\%) while they were the third most common lesions overall (19\%). This is similar to findings in other studies where NPDCs had been shown to have been the most common cysts among the nOCs. Other investigators found these lesions having been the most common nOCs $(2.2 \%)[15,16]$. According to the old classification, KCOT would have been the most common odontogenic cysts in this study. This was a histopathological analytical type of study and, therefore, it was likely that there were more biopsy specimens that were taken for microscopic examination bearing in mind the nature and aggressive behaviour of these lesions as compared to the RCs which, according to most other studies, should have been the most common lesions. The lesions occurred more in the mandible than the maxilla at a ratio of 3.4:1 while the male to female ratio was 1.04:1. This is in agreement with the findings of Jones et al. [2], in the United Kingdom. However, in that study, the mean age of presentation was 41 years which was much higher than our findings. In the present study, the peak age group was the 16 35-year one similar to findings of Jones et al. [2] (2006) which was at 11 - 30 years. Similarly, Ochsenius et al. [3] (2007) also found that the male: female ratio was 1.2:1, the peak age was in the second decade and the occurrence in the mandible was greater than in the maxilla (75.4\%).

DCs were the second most common lesions after KCOTs. They occurred mostly in the mandible (68\%) than the maxilla at a ratio of 2.1:1 which was similar to the findings in other published studies $[3,18,19]$. The peak age bracket for the occurrence of DCs was 8 - 28 years (mean $=22.8$ years) which was in agreement with other findings $[10,15]$. This indicates that the occurrence of DCs in the present study was similar to the occurrence in other population groups. The exact location of the DCs in the present study in the mandible or the maxilla could not be assessed since the data were obtained from patients' records or histology request forms which largely had information that was nonspecific.

RCs (20\%) were the fourth most common lesions among all the cysts but the third most common among the odontogenic cysts after the DCs. This was different from other findings where these cysts were the most common $[3,10,15,18,19]$. These cysts were more common among males (76\%) and occurred more commonly in the maxilla (72\%) than the mandible as it has been 
Table 2. Comparison of the relative occurrence of odontogenic and nonodontogenic cysts from the present study and selected references from other countries.

\begin{tabular}{|c|c|c|c|c|c|c|c|c|c|c|c|c|}
\hline & \multicolumn{2}{|c|}{$\begin{array}{c}\text { Grossmann et al. } \\
\text { (Brazil, current study) } 10\end{array}$} & \multicolumn{2}{|c|}{$\begin{array}{l}\text { Weir et al. } \\
\text { (US, 1987)17 }\end{array}$} & \multicolumn{2}{|c|}{$\begin{array}{c}\text { Daley et al. } \\
\text { (Canada, 1994) } 16\end{array}$} & \multicolumn{2}{|c|}{$\begin{array}{l}\text { Ledesma-Montes et al. } \\
\quad(\text { Mexico, 2000) } 15\end{array}$} & \multicolumn{2}{|c|}{$\begin{array}{l}\text { Jones et al. } \\
(U K, 2006) 2\end{array}$} & \multicolumn{2}{|c|}{$\begin{array}{l}\text { Our study, } \\
\text { Kenya }\end{array}$} \\
\hline & Cases & $\%$ & Cases & $\%$ & Cases & $\%$ & Cases & $\%$ & Cases & $\%$ & Cases & $\%$ \\
\hline $\begin{array}{l}\text { Radicular } \\
\text { cysts }\end{array}$ & 1772 & 62.0 & 892 & 52.8 & 4468 & 61.4 & 118 & 38.8 & 3724 & 52.3 & 29 & 15 \\
\hline $\begin{array}{l}\text { Dentigerous } \\
\text { cyst }\end{array}$ & 734 & 25.3 & 639 & 37.9 & 1662 & 22.8 & 108 & 35.5 & 1292 & 18.1 & 47 & 25 \\
\hline $\begin{array}{l}\text { Odontogenic } \\
\text { keratocyst }\end{array}$ & 208 & 7.2 & 157 & 9.3 & 335 & 4.6 & 57 & 18.8 & 828 & 11.6 & 53 & 28 \\
\hline $\begin{array}{l}\text { Nasopaltine } \\
\text { duct cyst }\end{array}$ & 64 & 2.2 & - & - & 295 & 4.0 & - & - & - & - & 35 & 19 \\
\hline $\begin{array}{c}\text { Calcifying } \\
\text { odontogenic cyst }\end{array}$ & 30 & 1.0 & - & - & - & - & - & - & 21 & 0.3 & 7 & 4 \\
\hline $\begin{array}{l}\text { Residual } \\
\text { cyst }\end{array}$ & - & - & - & - & - & - & 15 & 4.9 & 573 & 8.0 & 1 & 0.5 \\
\hline $\begin{array}{l}\text { Nasolabial } \\
\text { cyst }\end{array}$ & 29 & 1.0 & - & - & 7 & 0.09 & - & - & - & - & 3 & 2 \\
\hline $\begin{array}{l}\text { Eruption } \\
\text { cyst }\end{array}$ & 26 & 0.9 & - & - & 40 & 0.5 & 3 & 1.0 & 15 & 0.3 & 4 & 2 \\
\hline $\begin{array}{l}\text { Paradental } \\
\text { cyst }\end{array}$ & 19 & 0.7 & - & - & 33 & 0.5 & - & - & 402 & 5.6 & 2 & 1 \\
\hline $\begin{array}{l}\text { Gingival } \\
\text { cyst }\end{array}$ & 2 & 0.06 & - & - & 33 & 0.5 & - & - & 16 & 0.3 & 1 & 0.5 \\
\hline $\begin{array}{c}\text { Anerysmal } \\
\text { bone cyst }\end{array}$ & - & - & - & - & - & - & - & - & - & - & 3 & 2 \\
\hline $\begin{array}{l}\text { Traumatic } \\
\text { bone cyst }\end{array}$ & - & - & - & - & - & - & - & - & - & - & 2 & 1 \\
\hline
\end{tabular}

shown in other studies [10]. Tortorici et al. [19] (2008) in Italy found a predominance of these cysts among males $(53.5 \%)$ whence the preferred site was the anterior maxilla. Koseoglu et al. [20] in Turkey, also reported similar findings. Ochsenius [3] in Chile, having had the same findings stated that esthetic factors lead people to conserve these dental tissues, and therefore, they are more likely to subject them to long-term chronic inflammatory processes, without adequate resolutive endodontic treatment. In the present study it is likely that most patients opted to have their teeth exacted and few of the associated tissues of the extracted tooth are submitted for histopathologal evaluation. The mean age of occurrence of RCs was 26.6 years and the peak age was 20 - 35 years. Contrastingly, Jones et al. [2] in the United Kingdom, found a sharp increase in the incidence until the third decade and then a gradual decline from the fourth decade onwards while in Turkey Koseoglu [20] showed that RCs were rarely seen in individuals younger than 10 years, and that the lesions were most common between the ages of 20 and 60 years. Therefore, in many of the previous studies and the current one there is similarity in most aspects of RCs.

COCs constituted $5 \%$ of the odontogenic cysts and $4 \%$ of all the cysts and cyst-like lesions. The clinical and histologic features of the COC have generated disagreements and confusion regarding classification and terminology. Recently, it has been convincingly demonstrated that the COC contains 2 entities: a cyst and a neoplasm. In 1992, the WHO classified the COC as a neoplasm rather than a cyst and explained that the majority of the cases were in fact nonneoplastic [21]. Based on the new concept from the WHO (2005)14 that the COC contains not only a neoplasm but also a cyst, we proposed to include this lesion in our study. Jones et al. [2] in the UK found the frequency of occurrence to have been $0.3 \%$ and there was a predilection for males (1.63:1).

The NPDC (19\%) was the most common non-odontogenic cyst in the present study while it was the third most common among all the cysts and cyst-like lesions which was in agreement with other findings [2]. These lesions present with less aggressive behavior, showing low recurrence rates as well as a limited growth. The mean age for NPDC was 26.6 years with a peak at 16 20 years and a male to female ratio of 2.8:1.

\section{CONCLUSION}

The present results demonstrate that there is a wide range 
of OC and nOC, with some cysts having a predilection for age, gender, and localization. The demographic aspects and clinical characteristics of these cysts could be used as baseline data to obtain more epidemiologic information about the OC and the nOC, because there have been relatively few studies performed regarding their prevalence in the general population. RCs had a lower occurrence rate as compared to what other studies have found, although this may have been as a result of fewer tissues sampled for microscopic histological study from extracted teeth with peri-apical pathology.

\section{ACKNOWLEDGEMENTS}

We wish to acknowledge the supportive contribution by the statistician, Departmnt of public health and clinical epidemiology, University of Nairobi. We also recognize the work done to this manuscript by Sally Musinde.

\section{REFERENCES}

[1] Yazdani, J. and Kahnamouii, S.S. (2009) Developmental odontogenic cysts of jaws: A clinical study of 245 cases. Journal of Dental Research. Dental Clinics/Dental Prospectus, 3, 64-66.

[2] Jones, A.V., Craig, G.T. and Franklin, C.D. (2006) Range and demographics of odontogenic cysts diagnosed in a UK population over a 30-year period. Journal of Oral Pathology and Medicine, 35, 500-507. doi:10.1111/j.1600-0714.2006.00455.x

[3] Ochsenius, G., Escobar, E., Godoy, L. and Peñafiel, C. (2007) Odontogenic cysts: Analysis of 2.944 cases in Chile. Medicina Oral Patologia Oral y Cirugia Bucal, 12, 85-91.

[4] Padayachee, A. and Van Wyk, C.W. (1987) Two cystic lesions with features of both the botryoid odontogenic cyst and the central mucoepidermoid tumour: Sialoodontogenic cyst. Journal Oral Pathology, 16, 499-504. doi:10.1111/j.1600-0714.1987.tb00680.x

[5] Lacaita, M.G., Saverio, C., Gianfranco, F., et al. (2006) Infected paradental cysts in children: A clinicopathological study of 15 cases. British Journal of Oral and Maxillofacial Surgery, 44, 112-115. doi:10.1016/j.bjoms.2005.03.011

[6] Lucas, C. and Blum, T. (1929) Do all cysts of the jaws originate from the dental system. Journal of American Dental Association, 16, 659-661.

[7] Rushton, M. (1946) Solitary bone cysts in the mandible. British Dental Journal, 81, 37-49.

[8] Jaffe, H.L. and Lichtenstein, L. (1942) Solitary unicameral bone cyst with emphasis on the roentgen picture, the pathological appearance and the pathogenesis. Archival Surgery, 44, 1004-1025. doi:10.1001/archsurg.1942.01210240043003
[9] Bemier, J and Bhaskar S. (1958) Aneurysmal bone cyst of the mandible. Oral Surgery, 11, 1018. doi:10.1016/0030-4220(58)90142-7

[10] Grossmann, M.S., Machado, V.C., Guilherme, M.X., et al. (2007) Demographic profile of odontogenic and selected nonodontogenic cysts in a Brazilian population. Oral Surgery, Oral Medicine, Oral Pathology, Oral Radiology, and Endodontology, 104, 35-41. doi:10.1016/j.tripleo.2007.05.028

[11] Masayuki, T., Jun, C., Satoshi, M., Hiroko, Y., Motowo, N. and Takashi, S. (2008) Perlecan-rich epithelial linings as a background of proliferative potentials of keratocystic odontogenic tumor. Journal of Pathology and Medicine, 37, 287-293. doi:10.1111/j.1600-0714.2007.00620.x

[12] Narasimhan, P.A., Bobby, M.C., Leon B., et al. (2004) Molecular analysis to demonstrate that Odontogenic Keratocysts are neoplastic. Archives of Pathology and Laboratory Medicine, 128, 313-317.

[13] Toida, M. (1998) So-called calcifying odontogenic cyst: Review and discussion on the terminology and classification. Journal of Oral Pathology and Medicine, 27, 49-52. doi:10.1111/j.1600-0714.1998.tb02092.x

[14] Barnes, L., Eveson, J.W., Reichart, P., et al. (2005) Keratocystic odontogenic tumor. World Health Organization classification of tumors; Pathology and genetics of the head and neck tumors. IARC Press, Lyon, 308-309.

[15] Ledesma-Montes, C., Hernández-Guerrero, J.G. and Garcés-Ortíz, M. (2000) Clinico-pathologic study of odontogenic cysts in a mexican sample population. Archives of Medical Research, 31, 373-376. doi:10.1016/S0188-4409(00)00069-2

[16] Daley, T.D., Wysocki., G.P. and Pringle, G.A. (1994) Relative incidence of odontogenic tumors and oral jaw cysts in a Canadian population. Oral Surgery Oral Medicine Oral Pathology Oral Radiology Endodontology, 77, 276-280.

[17] Weir, L.C., Davemport, W.D. and Skinner, R.L. (1987) A diagnostic and epidemiologic survey of 15,783 oral lesions. Journal of American Dental Association, 115, 439442.

[18] Ogunsalu, C., Daisley, H., Kanhai, D., Mankee, M. and Maharaj, A. (2007) Reccurence of odontogenic keratocyst five cases in Jamaica. West Indian Medical Journal, 56, 927-934.

[19] Tortorici, S., Amodio E., Massanti, M., et al. (2008) Prevalence and distribution of odontogenic Cysts in Sicily 1986-2005. Journal of Oral Science, 50, 15-18. doi:10.2334/josnusd.50.15

[20] Koseoglu, B.G., Atalay, B. and Erdem, M.A. (2004) Odontogenic cysts: A clinical study of 90 cases. Journal of Oral Science, 46, 253-257. doi:10.2334/josnusd.46.253

[21] Kramer, I.R.H., Pindborg J.J. and Shear, M. (1992) Histological typing of odontogenic tumours. 2nd Edition, World Health Organization, Geneva. 